\title{
Multicultural Brazil in the BRICS Countries: Potentials for the Social Sciences and Humanities
}

Dr Ana Ivenicki ${ }^{\dagger}$

\section{Abstract}

This study argues a case for multiculturalism as a possible approach for addressing the complexities of societies such as the BRICS, taking Brazil as a case study. It contends that knowledge derived from such a study can benefit Social Studies and Humanities worldwide, particularly considering that cultural diversity has been increasingly present due to globalisation, internationalisation and growing mobility of groups of people, including refugees all over the world, requiring new epistemologies and narratives in research. The paper firstly analyses the concept of multiculturalism, discussing its perspectives from more liberal approaches up to more critical, postcolonial and decolonial perspectives that focus on the challenge of prejudices that operate in terms of control and denial of pluralism. It discusses the multicultural composition of the population of Brazil as a BRICS country, analysing its main geographical and population characteristics. The main focus of the paper is to delve in the ways that Brazilian educational policies have been trying to address both international standards and the valuing of cultural identities and equity-oriented approaches that are inclusive and multicultural. It particularly focuses on the National Plan for Education and of the recent project for higher education institutions (called "Future-se"). Finally, it concludes by pointing out tensions and possibilities of such Brazilian endeavours in the context of the BRICS countries. Such a study may be relevant comparatively, hopefully providing reflections for new epistemologies and the potential value of these for the Social Sciences and Humanities.

Keywords: Multiculturalism; Brazil; BRICS countries; New Epistemologies; Social Sciences and Humanities

\footnotetext{
${ }^{\dagger}$ Emeritus Professor, Education, Federal University of Rio de Janeiro, Researcher for the Brazilian National Council of Research (CNPq), Brazil, Email: aivenicki@gmail.com

(C) 2020 Ivenicki. This is an Open Access article distributed under the terms of the Creative Commons Attribution License (http://creativecommons.org/licenses/by/2.0), which permits unrestricted use, distribution, and reproduction in any medium, provided the original work is properly cited.
} 


\section{Introduction}

This research argues a case for multiculturalism as a possible approach for addressing the complexities of societies such as the BRICS, taking Brazil as a case study. It contends that knowledge derived from such a study can benefit worldwide in the domain of Social Studies and Humanities, particularly considering that cultural diversity has been increasingly present due to globalisation, internationalisation and growing mobility of groups of people, including refugees all over the world, requiring new epistemologies and narratives in research. The study firstly analyses the concept of multiculturalism, discussing its perspectives from more liberal approaches taking into account more critical, postcolonial and decolonial perspectives that focus on the challenge of prejudices that operate in terms of control and denial of pluralism. It discusses the multicultural composition of the population of Brazil as a BRICS country, analysing its main geographical and population characteristics. The primary focus of the study is to delve in the ways that Brazilian educational policies have been trying to address both international standards and the valuing of cultural identities and equityoriented approaches that are inclusive and multicultural. It mainly focuses on the National Plan for Education (Brazil, 2014), on the Base Nacional Comum Curricular (National Common Curricular Guidelines for Basic Education, free translation) (Brazil, 2017), and of the recent proposed project Future-se ("Prepare Yourself to the Future", free translation) (Brazil, 2019) for federal higher education institutions. It concludes by pointing out tensions and possibilities of such Brazilian endeavours in the context of the BRICS countries. Such a study may be relevant comparatively, hopefully providing reflections for new epistemologies and the potential value of these for the Social Sciences and Humanities.

As already stated, this study begins with the theorisation of the notion 'Multiculturalism', which I use as a lens to discuss cultural diversity in the countries of BRICS. Then this study turns to discuss multicultural Brazil as a case study within the countries of BRICS. This is followed by a discussion of recent educational policies in Brazil and possible multicultural contributions for the BRICS

\section{Multiculturalism as a Lens to Address Cultural Diversity in the BRICS Countries}

Multiculturalism is generally perceived as a set of policies and practices aimed at fostering an appreciation of cultural diversity and challenging stereotypes against identities on the lines of social class, race, ethnicity, gender, religion and other identity markers (Banks, 2004; Warren \& Canen, 2012; Ivenicki, 2018; 2019). Some approaches to multiculturalism include a folkloric, more liberal one, in which cultural diversity is fostered but inequality and discrimination are not touched upon; a critical one, in which racism and other forms of prejudices are the focus of the actions; and a post-colonial multicultural approach, which mainly posits that the opposition between collective identities categories such as black and white, male and female, developed and underdeveloped world, among others, are discursively constructed, and therefore, have to be deconstructed in order to allow for alternative discourses that challenge their claims to universal truth.

According to Stein (2017), the first approaches may provide only a "thin inclusion", which means that such liberal multicultural approaches include the discussion of cultural differences, but do not substantively attend to the differential, historically accumulated institutional power of different knowledges and knowledge communities. Critical post-colonial approaches, on the other hand, provide opportunities to develop an ecology of knowledge wherein different types of knowledge would be valued for the interventions that they enable within a particular context, rather than for their ability to represent reality in a universal perspective. In a similar vein, Aman (2017) contends that although the literature on interculturality strongly emphasises on engagement with the Other, it should take into account that difference 
is cultural but above all else, colonial. Therefore, in Latin America, the referred author contends that the indigenous population have been made more and more aware of the colonial difference since its construction. Bolivia, having made the furthest advancement in being the first state in the continent to recognise itself as plurinational in its constitution. In that sense, postcolonial multiculturalism or interculturalidad (Aman, 2017) has allowed an enhanced understanding of the importance to bridge cultural difference through intercultural dialogue, representing a move away from the monocultural, monoepistemic and pseudo-universal perspective based on colonial, European epistemologies.

Also, post-colonial multicultural perspectives highlight relational processes that produce subcultures and hybrid identities. Hybridity, here, means the provisionary, fluid and ever-changing boundaries that defy dicothomic and essencialised approaches to identity construction. It is a process that calls to the need to interrogate ideological underpinnings of that construction to bring forth transformational approaches that challenge the language of hegemony, prejudice and stereotyping.

The importance of multiculturalism is recognised in as much as societies have become more and more multicultural through factors such as the presence of immigration either for business and studies, but also in a context of increased number of refugees from different countries and cultures, within a globalised and post-colonial world. As discussed by Canen (2011), a postcolonial perspective seems to inform Castles' (2004) idea of transnational communities and citizenship perspective towards immigrants' identities and education. In that approach, the management of differences is taken beyond the idea of nation-states, recognising transnational groups as those "whose identity is not primarily based on attachment to a specific territory" ( $p$. 27).

Such an idea posits the existence of multiple identities, which should be recognised by laws that allow dual or multiple citizenships to immigrants. In fact, in that line of thought, migrants' children are perceived as identities that have complex needs related to plural identity markers in the lines of race, class, gender, ethnicity, cultural backgrounds, mother language and others, which engender prejudices they have to face and that have to be challenged by education.

In the same line of argument, Niens \& Chastenay (2008), cited by Canen (2011), contend that the development of multiple or superordinate identities has been acknowledged to be a means to combat ethnic divisions and conflict. Identity development is considered to be a key factor in citizenship education ...in societies where individuals bear multiple identities, crosscutting links should be created to instill transversal loyalties that go beyond community divisions and ensure social cohesion (...), [and] address multiple identities and conflict resolution competencies (...) (p. 521).

Such ideas seem to bear when talking about the BRICS countries. According to Steyn et al. (2018), the acronym BRICS refers to an international organisation that counts with developing and newly industrialised countries, namely: Brazil, Russia, India and China as its members, in 2006, when the organisation was established, and it was called BRIC. It changed to the BRICS organisation with the inclusion of South Africa as a full member in 2010. Also, according to the referred authors, the establishment of the BRICS organisation represented the founding of a comprehensive international group of nations with significant economic power and demographic weight in the world. Concerning education, the authors contend that such an organisation have the potential to improve education practices and provide both a conduit for impact-making research for scholars and supply for educational exchanges.

They stress the point that:

Although the member states of BRICS are clearly different, they share significant similarities. They are going through similar transformation processes because of their changing societies and also exert significant regional influences. And education plays a significant role in 
the transformation of their societies ( $p$. 289).

It should be pointed out that those countries present huge cultural with cultural values that have not been hegemonic in the world configuration but that are not homogeneous in their own societies. Internationalisation of educational policies in those countries could arguably present contributions in as much as they could strike a balance between the urge to be part of a broader international community but refrain from erasing their own distinct values, plural identities, languages and cultures.

As argued by Stein (2017), in a post-colonial multicultural perspective, such an international concept arguably entails efforts to disrupt colonial epistemic dominance and legitimise alternative epistemes that challenge the symbolic imaginary of the superiority of colonial knowledge and value cultural diversity. As discussed by Assié-Lumumba (2017), colonisation and its ensuing policies operate in absolute terms of control and denial of cultural pluralism. In order to defy it, it seems to be central that higher education policies in the BRICS countries embrace the internationalisation perspective in a way that both values their cultural diversity and challenges the assumptions that allowing room for plurality can be a self-defeating move (AssiéLumumba, 2017).

In that sense, being the fifth biggest country in the world and the one that has been receiving large waves of immigrants throughout its history (in the last two years it was the country that most received refugees seeking refuge from dire economic conditions and political persecution), Brazil is a case study to be analysed in the next sections. The study will try and address the extent to which those multicultural challenges and perspectives have been brought to bear on recent educational policies in higher education in that country, hopefully providing international and comparative insights for alternative frameworks that take cultural diversity on board, within the BRICS countries and elsewhere.

\section{Multicultural Brazil as a Case Study within the BRICS: Context and Educational Policies}

Brazil is a multicultural country. It is the fifth biggest country in the world and the biggest in South America, with a population of around 220 million people. It is divided into 26 states (and one federal district- Brasilia), each of them divided into several districts or municipalities. As argued elsewhere ( Canen, 2011, 2012; Ivenicki, 2015), Brazil has seen some waves of immigration into its territory throughout certain periods of its history. Having been conquered by the Portuguese in 1500, indigenous populations were affected by colonialism. However, many of them managed to survive up to these days, with different languages and singular cultures being in place. In the 19th Century, forced immigration of African peoples was undertaken for slavery purposes, which ended by 1888 , leaving most Blacks in poverty. Apart from those, Europeans and Japanese populations, among others, came to Brazil in the 20th Century, some searching for new economic opportunities, others fleeing from the world wars as well as ethnic and political conflicts and upheavals that affected Europe and Japan.

In the 20th Century, Brazil did not seem to perceive itself as an immigrant country, the populations having mostly been absorbed into Brazilian culture and ways of life. However, at the beginning of this 21st Century, the recent world economic crisis, coupled with the perceived Brazilian economic development have been factors that have attracted a new wave of immigrants, mainly from other countries of South America, Africa, and China. The total number of regular immigrants that legally live in Brazil is estimated at 700 thousand people. However, it should be noted that this number has increased in the last few years of this 21st Century due to the numbers of Venezuelans and Syrians fleeing from economic duress and political persecutions.

Three levels compound the public educational system in Brazil: federal, comprising technical and application schools generally linked to higher education institutions; state, comprising secondary education; and municipal, 
responsible for child and primary education. In terms of extension of years, primary education in Brazil takes nine years, secondary education three years, and higher education varies between undergraduate courses (ranging between 4 and 7 years, depending on the profession), and short technological courses (ranging between two and three academic years). Primary and Secondary schooling have been called Basic Education.

National curriculum guidelines are issued by the Ministry of Education, after long consultation with educational committees and the academic community through on-line and present seminars and reviews. Those ideas are analysed by the National Council of Education - which is composed by both educationalists elected by the educational community and representatives of the Presidency of Republic - and the Council gives its suggestions and appraisals and then sends all this material to the Ministry of Education, who can approve it or suggest further changes, and sends it to the Presidency of Republic to pass it as a law. The same process applies to assessment laws as well.

Concerning quality control in higher education $(\mathrm{HE})$, it has been at the centre of debates in Brazil and elsewhere. As suggested in previous research (Canen, 2012; Ivenicki, 2015), two aspects have to be borne in mind concerning the evaluation of quality in education in Brazil, namely: (i) the multiple systems that seem to coexist in the Brazilian higher education scenario; and (ii) the ways, in which both academic excellence and social inclusion have been dialectically intertwined within Brazilian higher education evaluation policies.

Concerning the first aspect, it is essential to note that in order to be called universities, higher education institutions should be research institutions that not only provide teaching but also mainly display a commitment to research. Higher education institutions without that emphasis are University Centers, Isolated Higher Education Schools, Technology Higher Education Centers, and Integrated Higher Education Schools. Universities - particularly those supported by the government (federal, state, and city institutions), as well as Catholic, private, and non-profit ones - have been associated with knowledge production through a healthy research-oriented perspective. On the other hand, higher education institutions created by the private sector had a boom in the seventies and the nineties.

In relation to the second aspect, it is important to state that a significant challenge to the evaluation of higher education in Brazil is to strike a balance between diversity/social inclusion with academic excellence at this level of education. As discussed by Canen (2012), according to the World Bank report of 2010, Brazil has only one-quarter of the adult population attending a higher education institute. That reflects both deficient social mobility and a tiny proportion of the labour force with tertiary level qualifications (8\%), creating severe impacts on productivity. The report argues that access to higher education institutions, particularly the prestigious free public ones, is skewed against students from low-income families.

As posited by the Canen (2012), it is noteworthy that quality control of education through largescale assessment of schools and higher education in Brazil has been increasingly highlighted as a government policy from the 1990s onwards. Following the democratisation process at the end of the 1980s, the Brazilian Constitution of 1988 and the Brazilian Law for National Education in 1996 have stressed the importance of assessing educational systems in order to promote efficient and democratic and equitable education for Brazilian students.

Side by side with that quality control conceived within the scope of homogenised, large-scale assessment instruments, another discourse seems to emerge in policies concerning higher education. In fact, as argued by Ivenicki (2015), given the emphasis on the social debt towards marginalised groups of adults and the need to prepare them for a globalised market society, a critical multicultural approach is perceived when Universities are called to be more inclusive so as to more clearly reflect Brazilian students' cultural, ethnic and racial diversity. In that sense, 
noteworthy are the measures to ensure the presence of black, indigenous and poor students coming from public government paid schools, through the higher education entrance quotas for those groups, compulsory for public universities.

In that sense, the ProUni (Program University for All) Program aims to place academically qualified low-income students into private tertiary education institutions, after they have been approved in the National final secondary education exam - the Exame Nacional do Ensino Médio - National Exam for Secondary Education (ENEM). They receive scholarships depending on the economic level of their family. The private institutions where they are placed are benefited in two ways: they expand their enrolment with subsidised fee-paying students who otherwise would not be able to pay; and private, for-profit institutions get tax exemptions in return for accepting scholarship students. The public university affirmative action programs vary from university to university. However, in general, they benefit students who attend public secondary schools and are members of demographic groups that have lower levels of education and lower-income, such as blacks, mulattos, and indigenous people.

According to previous studies (Canen, 2012; Ivenicki, 2015), that multicultural perspective can also be noticed through a cursory look at the ten-year strategic National Plan of Education in Brazil (Brazil, PNE, 2014), which is the ten year (2014-2024) national plan with intended educational principles, goals and strategies. Here, the emphasis shifts to the education of the marginalised young generation (particularly those between 18 and 24 years old) to prepare them both to professional/vocational and higher education paths. Goals particularly stress the importance of statistically increasing the roll of youngsters of that age group in higher education to $50 \%$, as well as doubling the rolls in the professional education of that same age group.

The mentioned document also deals with a critical multicultural perspective at the level of intentions, as noted in the goals related to the need to develop differentiated paths for indigenous groups' education, taking their ways of life and cultures onboard. It is also evident in those goals related to expanding school education for rural and black populations, "so as to foster sustainable development and the preservation of cultural identity" (goal, 7, strategy 7.17, Brazil, PNE, 2014). Such measures can implicitly reflect in the broader view of quality control of education in higher education in Brazil, being measured by the presence of an adult, mature students, from culturally and ethnically diverse backgrounds. Such a discourse arguably has the potential to provide an alternative meaning to the expression of quality control in higher education, within the context of culturally diverse societies, such as the Brazilian one.

\section{Recent Educational Policies in Brazil and Possible Multicultural Contributions for the BRICS}

The National Curricular Bases for Primary and Secondary Education (Brazil,2017; BCNN, 2017) were issued after discussions and polemics, and are now the national guidelines for schools in the whole of Brazil. According to the Ministry of Education site, the Common National Base contains the elements conducive to one's preparation for the continuity of studies and, as such, it should be implemented so that the development of basic competencies and skills, rather than the mere accumulation of previously established problem-solving arrangements, will be the ultimate objective of the learning process.

However, concerning the multicultural dimension of Brazilian society and the BRICS countries, criticisms made by the National Association of Post-Graduation (ANPEd, 2017)considered the most relevant research educational national association in Brazil - are relevant at this point. The referred organisation contends that the urge to present knowledge of Maths and Portuguese as the main foci of those curriculum guidelines is a far cry from a multicultural perspective. This is due to the fact that such a curriculum should value the plurality and diversity of Brazilian students. It should as well challenge homogenised approaches to the 
social, political, aesthetic and artistic knowledge in the country.

More recently, the presentation of a Program from the Ministry of Education named Future-se ("Prepare yourselves to the future", free translation) (Brazil, 2019) for the academic community concerning federal higher education in Brazil has also raised concerns.

As explained by Magno \& Melo (2019), the program is geared towards federal universities. It suggests outside financing and control for those, representing a threat to the autonomy of public universities' actions and programs. Even though the idea of promoting alternative sources for financially supporting those universities is not to be criticised, the referred authors stress the point that it should not compromise the government public funding of those. This is because the role of public universities in Brazil is linked to teaching, research and extension projects, the last ones geared towards the social commitment of higher education towards society, diversity and inclusion. It is important to point out that the extension dimension of public universities has not been mentioned in the Future-se (Brazil, 2019) project, which is organised around the axes of management, research and internationalisation.

For illustration purposes, as an aside to the importance of the extension perspective of public federal universities, some extension projects that have been developed in the last years can be mentioned at this point. Ivenicki (2019) discusses three of these projects, carried out as a partnership between a federal university in Rio and municipal authorities in three municipalities. They were arguably crucial for teacher continuing education and the production of municipal curricular guidelines in multicultural perspectives. In those experiences, the multicultural perspective went beyond a mere celebration of cultures. It allowed for the interrogation of racism and the challenge of essentialised identity construction, in postcolonial multicultural perspectives as suggested by authors such as Stein (2017). In those, municipal school actors not only recognised cultural diversity in the municipalities but pinpointed issues related to discrimination and low performance of groups of pupils, leading them to embrace a multicultural approach and suggest ways in which the curriculum could help build transformational identities.

Such extension projects can arguably be enhanced in public universities supported by government funds and geared towards valuing diversity. That is opposed to roles in which public universities have to fight for economic resources and be dependent on outside sources to legitimate what is (and what is not) considered as excellent knowledge. Such seems to be the case in the project Future-se (Brazil, 2019), where knowledge sees to be perceived in homogenised, market-oriented perspectives.

It should also be pointed out that the axe of internationalisation of higher education in the project of the Ministry of Education Future-se (Brazil, 2019) follows a trend in times of globalisation and the breaking of borders through technologies such as the internet and its social nets. However, in the document, that dimension is mainly understood in terms of aspects such as: providing language courses for university actors in order to foster the publishing of papers in international journals; and promoting interchange among national and international universities. Apart from those, the document also spells out the importance of bringing foreign relevant researchers to act in Brazilian universities, as well as offer scholarships for students in foreign universities. It refers to recognising disciplines and syllabuses that have been attended within international technological sites offered by universities with excellence recognised abroad. Finally, it mentions making quicker the recognition of certificates acquired outside Brazil in universities with recognised qualities.

However, it should be pointed out that the concept of internationalisation should not be confined to homogenised, technological and market-oriented approaches. In fact, we contend that internationalisation can have a few meanings, including a multicultural one. 
At this point, it should be clarified that the mentioned Brazilian project for higher education was submitted for public scrutiny and debate until the beginning of September 2019. Also, the intention manifested by the Ministry of Education is that it will not be compulsory for the federal universities to adopt it. In that sense, there is room for ample university debate.

Such educational policies in Brazil, taken as a case study, may well illustrate the challenges faced by recently industrialised countries such as the BRICS, with distinct cultural frameworks away from the dominant North hegemonic patterns. Tensions and contradictions in the way internationalisation of higher education have been conceived, illustrate the need to try and challenge homogenised approaches to it, to provide education, that is, inclusive and multicultural. The development of educational policies against complex political and economic backgrounds may be relevant to follow both in Brazil, in the BRICS countries and other countries, in a contemporary multicultural world.

\section{Conclusion}

The present study argued that a postcolonial multicultural perspective could enhance the BRICS contributions towards the internationalisation of education and higher education in transformational approaches. In order to develop the argument, it firstly discussed the epistemological tenets of multicultural perspectives in education, and it pinpointed the culturally diverse nature of the BRICS countries, mainly focusing on Brazil as a case study. It then delved in recent educational policies in Brzail pointing to the tensions between the aims to provide valuing of diversity and inclusion, on the one hand, and efforts towards internationalisation deploying homogenised approaches, on the other hand.

The analysis showed that educational policies used to reinforce, at least at the level of intentions, values of inclusion and cultural diversity. However, the study suggests that recent educational moves such as the project Future-se for federal public higher education seem to pend to the valuing of hegemonic, colonial values.

In fact, even though taking internationalisation as its main axe, that preliminary document with the project for higher education seems to focus on the concept of internationalisation in a given perspective. Internationalisation seems to be perceived there as economic expansion and epistemic erasure (Stein, 2017).

However, as pointed before, there is still scope for the rethinking of such a view of higher education, in a way that it could embed a concept of internationalisation in more multiculturally oriented approaches. In that way, cultural diversity within Brazilian and the BRICS countries should benefit from transformational approaches to education and social sciences, and therefore represent an original and distinctive contribution. On a final note, the present study may hopefully provide reflections for new epistemologies and the potential value of these for the Social Sciences and Humanities, within an increasingly plural world.

\section{References}

Aman, R. (2017). Colonial Differences in Intercultural Education: on interculturality in the Andes and the decolonization of intercultural dialogue, Comparative Education, 61 (S1), S103 - S121.

ANPEd - Associação Nacional de Pós-Graduação e Pesquisa em Educação (2017). A Associação Nacional de Pós-Graduação e Pesquisa em Educação (ANPEd) e a Base Nacional Comum Curricular (BNCC), a_anped_e_a_bncc_23.08.2017.pdf

Assié-Lumumba, N. T. (2017). The Ubuntu Paradigm and Comparative and International Education: epistemological challenges and opportunities in our field, Comparative Education, 61, (1), 1 - 21.

Banks, J. A. (2004). Introduction: Democratic Citizenship Education in Multicultural Societies. In: J. A. Banks (Ed.) Diversity and Citizenship Education. San Francisco: John Willey \& Sons, Inc. 3-15. 
Brazil (2014). Presidency of the Republic, Ministry of Education, Plano Nacional de Educação - 2014/2024 (National Plan for Education). Retrieved on 4 September 2019 from, http://pne.mec.gov.br.

Brazil (2017). Ministry of Education, Base Nacional Comum Curricular (Brazilian National Curricular Guidelines for Basic Education). Retrieved on 4 September 2019 from, http://basenacionalcomum.mec.gov.br.

Brazil (2019). Ministry of Education, Programa Future-se (Program "Prepare Yourself to the Future"). Retrieved on 4 September 2019 from, http://portal.mec.gov.br.

Canen, A. (2011). Boosting Immigrant Student Identities in Brazilian Schools: towards a multicultural framework for teacher education. In: Vandeyar, S. (Ed.), Hyphenated Selves: immigrant identities within education contexts. Amsterdam: Savusa/Rozenberg/UNISA Press, 149-164.

Canen, A. (2012). Brazil; lifelong learning and the role of University in Brazil: some reflections. In: Slowey, M. \& Schuetze, H. (Eds.). Global Perspectives on Higher Education and Lifelong Learners. London: Routledge, 266-278.

Castles, S. (2004), Migration, Citizenship, and Education. In: Banks, J. A. (ed.), Diversity and Citizenship Education. San Francisco: John Willey \& Sons, $17-48$.

Ivenicki, A. (2015). Adult Education and Cultural Diversity in Brazil: national policies and contributions of higher education. In: Milana, M. \& Nesbit, T. (Eds.). Global Perspectives on Adult Education and Learning Policy. 1ed.Londres: Palgrave MacMillan, 60-72. Ivencki, A. (2018). Multiculturalismo e Formação de Professores: dimensões, possibilidades e desafios na contemporaneidade, Revista Ensaio, 26 (100), 1151- 1167.

Ivenicki, A. (2019). Education Reform in Brazil: multicultural reflections. In: Ornelas, C. (Ed.), Politics of Education in Latin America: reforms, resistance and persistence. Series: Comparative and International Education: A diversity of voices, V. 49. Eds. Pitman, A; Pereyra, M.A. \& Majhanovich, S. Leiden: KoninklijkeBrill NV, $101-115$.

Magno, A.B.\& Melo, K. (2019). Projeto de Lei Preocupa Reitores e Mostra Pior Face do Future-se (Project of Law worries Rectors and shows the worst side of the Future-se), Jornal da ADUFRJ, 19/07/2019, Federal University of Rio de Janeiroo Edition, 3.

Niens, U., \& Chastenay, M.H. (2008). Educating for Peace? Citizenship Education in Quebec and Northern Ireland, Comparative Education Review 52(4), 519-540.

Stein, S. (2017). Challenges of Addressing Epistemic Dominance in Higher Education: considering the case of curriculum internationalization, Comparative Education, 61(S1), S25 - S50.

Steyn, H. J., Wolhuter, C., Vos, D., de Beer, L. \& Ivenicki, A. (2018). BRICS: A "Road and Belt" for South African Researchers in Education to be Involved in Impact-Making Research. In: Wolhuter, C. (Ed.), Raising the Impact of Education Research in Africa. Cape Town: AOSIS(Pty), $285-308$.

Warren, J. \& Canen, A. (2012). Racial Diversity and Education in Brazil. In: Banks, J. A.(Ed.), Encyclopedia of Diversity in Education, Washington DC: Sage Reference, 1, 262 - 265. 